\title{
Risks with Gynaecological problems on the health of University Students
}

\author{
Rukiye Hobek Akarsu ${ }^{1}$, Selda Yuzer Alsac ${ }^{2}$
}

\begin{abstract}
Objective: To determine the risk with gynecological problems on the health of female university students.

Methods: The study was conducted as a descriptive in university in Central Anatolia, Turkey. The research population was composed of 1305 female university students studying at a university in Central Anatolia. The study was conducted between January and March 2017. The data were collected through a questionnaire consisting of 23 questions prepared by the researchers to determine the socio-demographic characteristics of the participants and the risk with gynecological problems they encountered. Numerical and percentage statistics were used to analyze the data.

Results: About 65.4 percent of the female students in this study previously had gynecological examination, and 38.8 percent of them were diagnosed with gynaecological problems. It was found that 87.6 percent of the female students had risk with gynecological disorders. the most common ones being dysmenorrhoea (63.2\%), premenstrual syndrome (56.7\%), urinary tract infection $(22.4 \%)$, and polycystic ovarian syndrome (13\%), respectively.

Conclusions: It was found that nearly all the young girls had risk with gynecological problems and nearly half of them were diagnosed with different gynaecological disorders.
\end{abstract}

KEYWORDS: Young girls, Risk with gynecological problems, University female students.

How to cite this:

doi: https://doi.org/10.12669/pjms.35.3.834

Akarsu RH, Alsac SY. Risks with Gynaecological problems on the health of University Students. Pak J Med Sci. 2019;35(3):758-763. doi: https://doi.org/10.12669/pjms.35.3.834

This is an Open Access article distributed under the terms of the Creative Commons Attribution License (http://creativecommons.org/licenses/by/3.0), which permits unrestricted use, distribution, and reproduction in any medium, provided the original work is properly cited.

\section{INTRODUCTION}

1. Dr. Rukiye Hobek Akarsu, Department of Midwifery,

2. Dr. Selda Yuzer Alsac, Department of Nursing,

1,2: Faculty of Health Sciences, Yozgat Bozok University,

Yozgat, Turkey.

Correspondence:

Dr. Rukiye Hobek Akarsu, Assistant Professor, Department of Midwifery, Faculty of Health Sciences, Yozgat Bozok University,

Yozgat, Turkey.

E-mail: rukiye-hobek@hotmail.com

* Received for Publication:

* Revision Received:

* Revision Accepted:
October 18, 2018

April 4, 2019

April 10, 2019
The World Health Organization defines the 10-19 age group as the "Adolescent" group and the 15-24 age group as the "Young" group. Due to the intersection of adolescent and youth ages, the 10-24 age group is considered as "Young People". In Turkey, the share of the 10-24 age group within the total population is $21.1 \%$. This rate is fairly high, meaning that one in every five people is in the youth age group. ${ }^{2}$ During the youth period, which is generally considered as the transition period from childhood to adulthood. ${ }^{3}$ Young peoples experience not only changes in brain, neuro-endocrine system and hormone concentrations but also physical and emotional changes and risks with gynecological problems that affect reproductive health and 
social life. ${ }^{4}$ Adolescents encounter some risks with gynecological problems such as menstrual problems, vaginal discharge and infections, pelvic mass and ovarian cysts, trauma and sexual abuse, genital system anomalies, abdominal and pelvic pain, adolescent pregnancies, breast problems, and early and late puberty. ${ }^{5}$ In a study $33.4 \%$ of the adolescents consulted a doctor with complaints of menstrual disorder and that 2.8 percent of all the patients were hospitalized for treatment. $^{6}$

Furthermore, as revealed by the study, the young population is generally perceived as a healthy group that does not require health care services, and thus they cannot adequately benefit from these services. ${ }^{7}$ For this reason, the diagnosis of the gynecological problems whose onset is rooted in this period may be delayed, leading to higher mortality or morbidity at adult ages. However, it must be noted that the majority of the health problems experienced in this period may be prevented. ${ }^{8}$

It is important for young womens to receive appropriate health care so that they can cope with the gynecological problems they may experience during this period. Also, it is important to know the risks with gynecological problems that can be encountered frequently so that effective interventions can be made to prevent these problems. ${ }^{5}$

Early detection and treatment of problems and taking the necessary precautions against the problems improve both the health level and life quality of young women. Healthy young womens can contribute to community health by increasing women's health.

There are few studies on risk with gynecological problems in young women in the world, or a limited number of studies that determine the prevalence of extensive risk with gynecologic problem. This study aimed to determinate the risk with gynecological disorders in female university students.

\section{METHODS}

We conducted a descriptive study in university in Central Anatolia, Turkey. The research population was composed of female university students studying at a university in Central Anatolia. It was planned to include all female students in the university which were 1612 in number.

\section{Inclusion Criteria}

- Being 18 or older

- Accepting to participate in the study

- Continuing undergraduate education

\section{Exclusion criteria}

- Under 18 years old

- Having communication problems

- Having physical disabilities.

The study was completed with 1305 female students with a response rate of $80.9 \%$ of the universe was reached.

The data was collected with a questionnaire, consisting of 23 questions aimed to determine the age of the participants, the place they live in and the gynecological problems they have. The most common gynecological problems were listed and the definition and symptoms of each problem was given in parenthesis. For example, Premenstrual Syndrome (a condition characterized by some emotional changes that start a few days before menstruation and which could continue throughout the menstruation such as edema, headache, nervousness and tension), or urinary tract infection (a condition characterized by foul discharge, inguinal pain, and urinary burning). Gynecological problems diagnosed by a doctor were investigated separately, e.g., physician-diagnosed polycystic ovarian syndrome. The questionnaire was distributed among the students selected from the faculties or schools based on the simple random numbers table during the lesson breaks. The data was entered into a computer and numerical and percentage statistics were used to analyze the data.

The participants were informed about the aim of the study and their oral and written consent was obtained by asking them to sign the participant consent Form. The written permission was received from Bozok University and the ethical permission was obtained from Bozok University Clinical Sciences Ethical Committee. (Ethical committee registration number: 38812373050.01/1).

Statistical Package for Social Science (SPSS) 21 was used to analyze the data. The KolmogorovSmirnov test and Shapiro-Wilk test were used to determine the normal distribution of the data. Descriptive statistics (percentage, average, and standard deviation) $(\mathrm{p}<0.05)$. 


\section{RESULTS}

Socio-demographic data of the female students in the study is given in Table-I. The average age of the students was $19.7 \pm 0.45$, and the average of Body Mass Index (BMI) was found to be 21.4 \pm 3.1 . 99.2 percent of the students were single; $66.7 \%$ of them perceived their economic situation as good; and $64.6 \%$ of them stayed in the state dormitory.

Health behaviors of the female students in our study is shown in Table-II. It was found that $90.4 \%$ of the students did not smoke, and $98.5 \%$ of the students stated that they do not use alcohol. The study further found that $75.8 \%$ of the participants do not do regular exercise.

The gynecological characteristics of the female students in this study are given in Table-III. The average menstrual age of the participants was found to be $13.5 \pm 1.31$. About 71.6 percent of the participants stated that their menstrual cycle was regular, $65.4 \%$ of the female students in this study further stated that they had a gynecological examination before and $38.8 \%$ reported that they had a diagnosed gynecological problem. Furthermore, $83.4 \%$ of the participants believed that it is necessary to have regular gynecological examination and $46.9 \%$ of them believed that examination should be once in every six months. Moreover, our study revealed that $69.2 \%$ of

Table-I: Socio-demographic characteristics of the young womens.

\begin{tabular}{lcc}
\hline Socio-demographic characteristics & $n$ & $\%$ \\
\hline Age & $19.7 \pm 0.45$ \\
BMI & $21.4 \pm 3.1$ \\
Marital Status & \multicolumn{2}{c}{} \\
$\quad$ Married & 11 & 0.8 \\
Single & 1294 & 99.2 \\
Economic Status & & \\
Good & 359 & 27.5 \\
Average & 857 & 66.7 \\
Bad & 89 & 6.9 \\
Pce Residence & & \\
Village & 270 & 207 \\
Town & 411 & 31.5 \\
City & 624 & 47.8 \\
Accommodation & & \\
State Dormitory & 843 & 64.6 \\
Private Dormitory & 329 & 25.2 \\
House & 133 & 10.2 \\
\hline Total & 1305 & 100.0 \\
\hline
\end{tabular}

the female students do not know breast selfexamination (BSE), that $82.8 \%$ of those who know BSE do not do it, that $9.7 \%$ of the students had gynecological cancer history in their family, and that $69.8 \%$ of those who had gynecological cancer also had breast cancer.

The gynecological problems experienced by the female students in this study are shown in Table-IV. It was revealed that $87.6 \%$ of the participants had a gynecological problem. The most widespread gynecological problems were dysmenorrhoea $(63.2 \%)$ premenstrual syndrome (PMS) (56.7\%), urinary tract infection $(22.4 \%)$ respectively.

\section{DISCUSSION}

The study showed that $86.7 \%$ of the young female students in this study were at risk of gynecological problem. Demir et $\mathrm{al}^{,}{ }^{9}$ has reported that regular exercise, reduction in caffeine and alcohol consumption, not smoking, regular and balanced diet, and consumption of fresh fruit and vegetable reduces the risk with gynecological problems. It was observed that

Table-II: Health behaviors of the young womens in the study.

\begin{tabular}{lcc}
\hline Health behaviors & $n$ & $\%$ \\
\hline Smoking & 125 & 9.6 \\
Smoker & 1180 & 90.4 \\
Non-smoker & $9.03 \pm 8.7$ \\
Number of Cigarettes* (day) & \multicolumn{2}{c}{} \\
Alcohol consumption & 19 & 1.5 \\
Yes & 1286 & 98.5 \\
No & & \\
Doing Exercise & 316 & 24.2 \\
Yes & 989 & 75.8 \\
No & & \\
Frequency of Doing Exercise** & 78 & 24.7 \\
Everyday & 133 & 42.0 \\
Occasionally & 48 & 15.2 \\
Once a week & 57 & 18.0 \\
Twice a week and more & & \\
Mostly preferred food types & 575 & 44.1 \\
Legume & 469 & 35.9 \\
Vegetable- Fruit & 261 & 20.0 \\
Meat and Meat Products & 1305 & 100 \\
\hline Total & & \\
\hline * percentages (n=125) ** percentages (n=316) & \\
\hline & &
\end{tabular}


Table-III: Gynecological characteristics of the young womens.

\begin{tabular}{|c|c|c|}
\hline Gynecological Characteristics & $n$ & $\%$ \\
\hline Menstrual age & \multicolumn{2}{|c|}{$13.5 \pm 1.31$} \\
\hline \multicolumn{3}{|l|}{ Having regular menstrual cycles } \\
\hline Regular & 934 & 71.6 \\
\hline Irregular & 371 & 28.4 \\
\hline \multicolumn{3}{|l|}{ Time between the menstrual cycles } \\
\hline Less than 28 days & 383 & 29.3 \\
\hline Between 28-34 days & 796 & 61.0 \\
\hline 35 days and more & 126 & 9.7 \\
\hline Length of menstrual periods & \multicolumn{2}{|c|}{$5.7 \pm 1.4$} \\
\hline \multicolumn{3}{|l|}{ Having a gynecological examination before } \\
\hline Yes & 451 & 34.6 \\
\hline No & 854 & 65.4 \\
\hline \multicolumn{3}{|l|}{ Having a gynecological Problem diagnosis* } \\
\hline Diagnosed & 175 & 38.8 \\
\hline Not diagnosed & 276 & 61.2 \\
\hline \multicolumn{3}{|c|}{ Opinions on having regular gynecological examination } \\
\hline Necessary & 1088 & 83.4 \\
\hline Not necessary & 217 & 16.6 \\
\hline \multicolumn{3}{|l|}{$\begin{array}{l}\text { Opinions on the frequency of having regular } \\
\text { gynecological examination }\end{array}$} \\
\hline Necessary once in every 6 months & 510 & 46.9 \\
\hline Necessary once a year & 449 & 41.3 \\
\hline Necessary when there is a health problem & 129 & 11.9 \\
\hline \multicolumn{3}{|l|}{ Knowing about BSE } \\
\hline Yes & 402 & 30.8 \\
\hline No & 903 & 69.2 \\
\hline \multicolumn{3}{|l|}{ Doing BSE ${ }^{* * *}$} \\
\hline Yes & 69 & 17.2 \\
\hline No & 333 & 82.8 \\
\hline \multicolumn{3}{|l|}{ Having Gynecological cancer in the family } \\
\hline Yes & 126 & 9.7 \\
\hline No & 1179 & 90.3 \\
\hline \multicolumn{3}{|c|}{ Type of the gynecological cancer in the family $* * * *$} \\
\hline Breast Cancer & 88 & 69.8 \\
\hline Uterus Cancer & 33 & 26.2 \\
\hline Ovarian Cancer & 3 & 2.4 \\
\hline Cervix Cancer & 2 & 1.6 \\
\hline$\overline{\text { Total }}$ & 1305 & $\overline{100.0}$ \\
\hline
\end{tabular}

*Percentages were taken over $n=451$,

** Percentages were taken over $n=1088$,

*** Percentages were taken over $n=402$,

$* * * *$ Percentages were taken over $n=126$.

alcohol and smoking rates are low. However increased exercise and balanced nutrition was also low. This situation may have increased the risk of gynecological problems.
Table-IV: Gynecological problems of the young womens.

\begin{tabular}{lcc}
\hline Gynecological Problems & $n$ & $\%$ \\
\hline Having a risk with gynecological problem & & \\
Yes & 1143 & 87.6 \\
No & 162 & 12.7 \\
Risk with Gynecological Problems* & & \\
Dysmenorrhea & 825 & 63.2 \\
PMS & 740 & 56.7 \\
Urinary tract infection & 299 & 22.4 \\
Polycystic ovarian syndrome & 170 & 13.0 \\
Physician-diagnosed polycystic ovarian & 46 & 3.5 \\
Amenorrhea & 145 & 11.1 \\
Fungal infection & 115 & 8.8 \\
Bacterial infection & 37 & 2.8 \\
Parasitic infection & 33 & 2.5 \\
Genital Wart & 30 & 2.3 \\
Physician-diagnosed myoma & 13 & 1.0 \\
Physician-diagnosed pelvic & 11 & 0.8 \\
$\quad$ inflammatory disease & & \\
Physician-diagnosed Breast Mass & 10 & 0.8 \\
Chronic Pelvic Pain & 9 & 0.7 \\
\hline Total & 1305 & 100.0 \\
\hline
\end{tabular}

*More than one response was given to the question.

This study revealed that $34.6 \%$ of female students had a gynecological examination due to a health problem and that $38.8 \%$ were diagnosed with a gynecological disorders About half of the students stated that it is necessary to have a gynecological examination every six months. Demiray et al. ${ }^{10}$ found that about one third of women, the majority of whom are aged between 31-40, have a gynecological examination. As gynecological problems are considered to be embarrassing in Turkey, the rate of seeing a gynecologist is low. This study also revealed that although half of the participants believe that a gynecological examination is necessary at least once in six months, only about one third of them had seen a gynecologist so far.

The study also showed that two thirds of the university students do not know how to do BSE and that only $17.2 \%$ of those who know BSE actually do it. Alpteker et al. ${ }^{11}$ has demonstrated that $19.7 \%$ of those who know how to do BSE do not actually do it. About half of the female students studying at university do not know BSE and the majority of those who know it do not do it.

It was also found that $10 \%$ of the participants had a family history of gynecological cancer and that $69.8 \%$ of these cancer were breast cancer. Although breast cancer was found to have a higher percentage compared to other cancer types, female students do not know BSE and those who know BSE do not do it, which is a striking finding. This 
may be attributed to the fact that woman breast is perceived as the symbol of youth and sexual attraction, and thus it is a sin, shame, and a taboo to touch it.

Furthermore, it was revealed that almost all the female students in the study had at least one gynecological problem. The gynecological problems experienced vary, the most common ones being dysmenorrhoea (63.2\%) and PMS (56.7\%). Previous studies have also found the prevalence of dysmenorrhoea to be between $52.07 \%$ and $86.9 \%$ and PMS to be between $8.75 \%$ and $85 \% .^{12-15}$

The study conducted in Turkey to determine the gynecological problems revealed that the majority of the adolescents who had the dysmenorrhoea problem also had PMS. ${ }^{9}$ As revealed by this study, the prevalence of PMS and dysmenorrhoea is close to each other, implying that young womens may be experiencing these problems at the same time.

We found that $22.4 \%$ of the female students in our study had the symptoms of urinary tract infection. Despite the detailed literature review, we could not find any recent studies conducted to determine the prevalence of urinary tract infection problem in young womens. However, the studies carried out with young womens and adolescents found the prevalence of urinary tract infection to be between $2 \%$ and 30 percent. ${ }^{16-18}$ The study also revealed similar findings as $14.1 \%$ of the students had infections such as fungus infection $(8.8 \%)$, bacterial infection $(2.8 \%)$, and parasitic infection $(2.5 \%)$. Moreira et al. ${ }^{19}$ found bacterial $(5 \%)$ and fungus infection $(4 \%)$ in adolescents. The study findings coincide with those in the literature.

The rate of physician-diagnosed polycystic ovarian syndrome (POS) was found to be $3.5 \%$. In another study, the prevalence of diagnosed POS was found to be $2.6 \%$ in women aged $25-34 .{ }^{20}$ In the literature, the prevalence of POS in women at reproductive age was found as 4 to 10 percent. ${ }^{21,22}$ In this study, the rate of the young womens who were not given a diagnosis by a physician, but who had POS symptoms was found to be $13 \%$. It is believed that this rate may increase when detailed examinations are conducted.

One of the important health problems in adolescent womens is the sexually transmitted diseases (STD). A study found that $24 \%$ of sexually active adolescent womens had STD, the most common one being human papilloma virus (HPV) infection. ${ }^{23,24}$ In this study, $2.3 \%$ of the womens stated that they had the symptoms of genital wart. The number of studies conducted in Turkey on
STD is limited. As revealed by this study, the rate of HPV in Turkey is low compared to the other countries in the literature. This may be attributed to the fact that in societies where sex is associated with marriage, the rate of adolescents with active sex life is low.

\section{CONCLUSION}

It was revealed that young womens in this study had high risk of gynecological disorders. Risk with gynecological problems can lead to worse health conditions. It is suggested that reproductive health and risk with gynecological problems for young women should be initiated in the preadolescence period and that the university health education programs should be organized to cover interventions to prevent risk with gynecological disorders. It is recommended that prevalence studies specific to risk with gynecological problems common in young womens be conducted with larger samples and different populations.

\section{Grant Support \& Financial Disclosures: None.}

\section{REFERENCES}

1. World Health Organization, Promoting the Health of Young People in Custody. 2012. URL: http://www.euro.who.int/ document/e81703.pdf. Nov 30, 20018.

2. Turkish Statistical Institute. URL: https://biruni.tuik.gov. tr/nufusapp/idari.zul. Nov 28, 2018.

3. Ministry of Health. General Directorate of Mother and Child Health and Family Planning: Sexual Health/Reproductive Health. URL: https://sbu.saglik.gov.tr/Ekutuphane/ kitaplar/a\%C3\%A7sap41.pdf. Nov 5, 2018

4. Lerner RM, Steinberg L. (eds) Puberty and Psychological Development. In: Handbook of Adolescent Psychology. Hoboken: New Jersey, John Wiley\&Sons. 2004;15-44.

5. Tekirdag AI. Approach to common gynecological problems in adolescents. JOPP. 2010;2(1):13-20.

6. Altay MM, Haberal A. Abnormal uterine bleeding in adolescents: Treatment with combined oral contraceptive pills is effective even in hospitalized patients with bleeding disorders. Turk J Med Sci. 2008;38(5):431-435.

7. Celik DB, Dag G, Demirel G. The effects on gynecological problems and reproductive health in adolescence. Sisli Etfal Hospital Medical Bulletin. 2013;47(4):157-166. doi: 10.5350/ SEMB2013470401

8. Parlaz EA, Tekgul N, Karademirci E, Ongel K. Adolescence Period: Physical Growth, psychological and social development process. Turkisch Family Physician. 2012;3(4):10-15.

9. Demir B, Algul LY, Güvendag GE. Investigation of premenstrual syndrome incidence and affecting factors in health workers. Turk Soc Obstet Gynecol. 2006;3(4):262-270.

10. Demiray A, Korhan EA, Cevik K, Khorshid L, Yucebilgin MS. Comparison of state anxiety due to gynecological examination in patients who applied to public and private institutions. Electron J Vocat Coll. 2014;4(4):122-129. doi:10.17339/ejovoc. 95120. 
11. Alpteker H, Gumus D, Dogan S. Examination of breast cancer and breast self-examination information and practices of female students. J Breast Health. 2011;7(3):176-181.

12. Erenel A, Senturk I. Health High School Students Experienced Dysmenorrhoea and Their Applications to Cope with it. Hacettepe Univ J Nurs Faculty. 2007;14(2):48-60.

13. Yilmaz T, Yazici S. Characteristics of dysmenorrhea situations of midwifery and nursing students. J Ataturk Univ Nurs School. 2008;11(3):1-8.

14. Antai AB, Udezi AW, Ekanem EE, Okon UJ, Umoiyoho AU. Premenstrual syndrome: prevelance in students of the university of Calabar, Negeria. Afr J Biomed Res. 2004;7:45-50.

15. Chandraratne N, Gunawardena N. Premenstrual syndrome: the experience from a sample of Sri Lanka adolescents. J Pediatr Adolesc Gynecol. 2011;24(5):304-310. doi:10.1016/j.jpag.2011.05.010.

16. Beetz R. May we go on with antibacterial prophylaxis for urinary tract infections? Pediatr Nephrol. 2006;21:5-13. doi:10.1007/s00467-005-2083-6.

17. Aiyegoro OA, Igbinosa OO, Ogunmwonyi IN, Ezamba CC, Ekwealor I.A. Incidence of urinary tract infections (UTI) among children and adolescents in Ile-Ife, Nigeria. Afr J Microbiol Res. 2007;1(2):13-19.

18. Mishra OP, Abhinay A, Prasad R. Urinary infections in children. Indian J Pediatr. 2013;80:838-843. doi:10.1007/ s12098-013-1118-4.

19. Mascarenhas RE, Machado MSC, Costa e Silva BFB, Pimentel R, Ferreira TT, Leoni FMS, et al. Prevalence and risk factors for bacterial vaginosis and other vulvovaginitis in a population of sexually active adolescents from Salvador, Bahia, Brazil. Infect Dis Obstet Gynecol. 2012;8(1):378640. doi: 10.1155/2012/378640
20. Christensen SB, Black MH, Smith N, Martinez MM, Jacobsen SJ, Porter AH. Prevalence of polycystic ovary syndrome in adolescents. Fertil Steril. 2013;100(2):470-477. doi: 10.1016/j.fertnstert.2013.04.001.

21. Tharian K, Warner J. Polycystic ovarian syndrome in adolescent girls. Pediatr Child Health. 2011;21(7):309-314. doi:10.1016/j.paed.2011.01.005.

22. Joshi B, Mukherjee S, Patil A, Purandare A, Chauhan S, Vaidya R. A cross-sectional study of polycystic ovarian syndrome among adolescent and young girls in Mumbai, India. Indian J Endocrinol Metab. 2014;18(3):317. doi:10.4103/2230-8210.131162.

23. Forhan SE, Gottlieb SL, Sternberg MR, Xu F, Datta SD, McQuillan GM, et al. Prevalence of sexually transmitted infections among female adolescents aged 14 to 19 in the United States. Pediatrics. 2009;124:1505-1512. doi:10.1542/ peds.2009-0674.

24. Manyike P, Chinawa J, Aniwada E, Udechukwu NP, Odetunde $\mathrm{O}$, Chinawa A. Child sexual abuse among adolescents in southeast. Nigeria: A concealed public health behavioral issue. Pak J Med Sci. 2015;31(4):822-832. doi:10.12669/pjms.314.7115.

\section{Author`s Contribution:}

RHA conceived, designed and did statistical analysis \& editing of manuscript \& did review and final approval of manuscript.

SYA did data collection and manuscript writing. 